\title{
Phase II study of sequential chemotherapy with docetaxel- estramustine followed by mitoxantrone-prednisone in patients with advanced hormone-refractory prostate cancer
}

\author{
L Galli', A Fontana*,', C Galli', L Landi', E Fontana', A Antonuzzo', M Andreuccetti', E Aitini' ${ }^{2}$ R Barbieri', \\ R Di Marsico' and A Falcone ${ }^{1,3}$
}

'Division of Medical Oncology, Azienda USL 6 of Livorno, Livorno 57100 , Italy; ${ }^{2}$ Division of Medical Oncology and Hematology, Azienda Ospedaliera C Poma Mantova, Italy; ${ }^{3}$ Department of Oncology Transplants and New Technologies in Medicine, University of Pisa, Italy

\begin{abstract}
Sequential chemotherapy may improve treatment efficacy avoiding the additive toxicity associated with concomitant polichemotherapy in hormone-refractory prostate cancer (HRPC). Forty patients received docetaxel $30 \mathrm{mg} \mathrm{m}^{-2}$ intravenous (i.v.), weekly, plus estramustine $280 \mathrm{mg}$ twice daily for 12 weeks. After 2 weeks rest, patients with a decline or stable PSA were treated with mitoxantrone $12 \mathrm{mg} \mathrm{m}^{-2}$ i.v. every 3 weeks plus prednisone $5 \mathrm{mg}$ twice daily for 12 cycles. Forty patients were assessable for toxicity after docetaxel/estramustine. Main toxicities were grade 3-4 AST/ALT or bilirubin increase in seven patients (17.5\%) and deep venous thrombosis (DVT) in four patients (10\%). Twenty-seven patients received mitoxantrone/prednisone. Main toxicities included DVT in one patient (3.7\%) and congestive heart failure in two patients (7\%). Thirty-nine patients were assessable for PSA response. Twenty-nine patients $(72.5 \%$; 95\% Cl 63-82\%) obtained a $\geqslant 50 \%$ PSA decline with 15 patients (37.5\%; 95\% Cl 20-50\%) that demonstrated a $\geqslant 90 \%$ decrease. Median progression-free and overall survival were respectively 7.0 ( $95 \% \mathrm{Cl} 5.8-8.2$ months) and 19.2 months ( $95 \% \mathrm{Cl}$ 13.9-24.3 months). In conclusion, although this regimen demonstrated a favourable toxicity profile, sequential administration of mitoxantrone is not able to improve docetaxel activity in patients with HRPC.
\end{abstract}

British Journal of Cancer (2007) 97, 1613-1617. doi: I0.1038/sj.bjc.6604090 www.bjcancer.com

Published online 20 November 2007

(c) 2007 Cancer Research UK

Keywords: prostate cancer; docetaxel; estramustine; mitoxantrone; sequential chemotherapy

Prostate cancer is the most common cancer in men and the third estimated cause of death of cancer in the United States in 2006 (Jemal et al, 2006). Androgen ablation is the standard initial management for metastatic prostate cancer; however, all patients develop hormone-refractory disease after a median time of 18-24 months. In such condition, second-line hormonal agents lead to low response rates and brief disease control and multidisciplinary treatment includes symptomatic treatments, bisphosphonates, radiotherapy, radioisotopes and chemotherapy (Pienta and Smith, 2005).

Two randomised phase III trials of mitoxantrone plus corticosteroids $v s$ corticosteroids alone (Tannock et al, 1996; Kantoff et al, 1999) demonstrated an improvement in quality of life, pain relief and PSA response rate in favour of mitoxantrone regimens. Although this significant palliative activity was not matched with an improvement in survival, mitoxantrone plus prednisone was considered the standard chemotherapy regimen for hormonerefractory prostate cancer (HRPC) for a long time. New chemotherapy agents such as docetaxel combined with estramustine showed interesting activity in phase II trials. They shared

*Correspondence: Dr A Fontana; E-mail: andrea.fontana@aruba.it Received 2 July 2007; revised 24 September 2007; accepted 17 October 2007; published online 20 November 2007 similar mechanisms of action (microtubule stabilisation and mitotic process disruption) and showed synergistic activity in prostate cancer cell lines (Stearns et al, 1985; Kreis et al, 1997). Phase II studies of single agent docetaxel, given every 3 weeks or as a weekly schedule, showed a PSA response rate of about $45 \%$ and an interesting objective response rate, particularly for the weekly regimen (40\%) (Picus and Schultz, 1999; Beer et al, 2001). Combination of docetaxel with estramustine led to a very promising activity. A PSA response rate between 45 and $68 \%$ with an objective response rate of $20-55 \%$ was observed in every 3 weeks docetaxel plus estramustine phase II trials (Petrylak et al, 2000; Savarese et al, 2001; Sitki Copur et al, 2001; Sinibaldi et al, 2002). Moreover, weekly docetaxel plus estramustine produced a $\geqslant 50 \%$ decline in PSA in $76 \%$ of patients and an objective response rate of $58 \%$ without grade 4 toxicity (Sitki Copur et al, 2001). Recently, two randomised phase III trials have demonstrated a significant improvement in overall survival (OS), pain control, quality of life and PSA response, for docetaxel-based chemotherapy, which has become the standard treatment for metastatic HRPC (Petrylak et al, 2004; Tannock et al, 2004). However, no second-line chemotherapy is currently available for HRPC, and mitoxantrone has demonstrated a PSA response rate of $12-20 \%$ even in taxane-resistant patients showing a noncomplete cross resistance between docetaxel and mitoxantrone (Michels et al, 2006; Rosenberg et al, 2006). In the attempt to improve treatment 
activity, combination of three (Colleoni et al, 1997; Smith et al, 1999; Segawa et al, 2005) or more (Smith et al, 2003) chemotherapy agents was investigated in phase II studies. These trials reported a PSA response rate in $58-65 \%$ of patients and a measurable disease response between 32 and $58 \%$, but an incidence of grade 3-4 haematological toxicity in $12-48 \%$ of patients. Moreover, febrile neutropaenia in $15 \%$ of patient and one toxic death were reported in one study (Colleoni et al, 1997). The significant toxicity observed with polichemotherapy regimens makes the combination of docetaxel plus estramustine and mitoxantrone probably not easily feasible, particularly in this often elderly and 'fragile' population of patients. At the time of study design, no data concerning docetaxel efficacy or better schedule of administration were available. We design this sequential phase II study of 12 weeks docetaxel regimen in accordance to previous findings by Beer et al (2001) and Sitki Copur et al (2001). Moreover, we administered sequential mitoxantrone/prednisone in case of response of stable disease to expose patients, who mostly benefit from docetaxel chemotherapy, to both agents at therapeutic doses, avoiding additive toxicity and potentially increasing activity.

\section{MATERIALS AND METHODS}

\section{Eligibility criteria}

Eligible patients had histologically documented adenocarcinoma of the prostate and had failed to benefit from androgen ablation and subsequent antiandrogen withdrawal for their metastatic or locally advanced disease. All patients met the following criteria: age $\geqslant 18$ years; measurable disease progression or PSA serum level increasing on three consecutive measurements at least 2 weeks apart; PSA $\geqslant 10 \mathrm{ng} \mathrm{ml}^{-1}$; Eastern Cooperative Oncology Group (ECOG) performance status $\leqslant 2$; no prior chemotherapy included estramustine; discontinued prior antiandrogen treatment by at least 4 weeks ( 6 weeks in the case of bicalutamide); adequate bone marrow function (leucocytes $\geqslant 3500 \mathrm{ml}^{-1}$, neutrophil count $\geqslant 1500 \mathrm{ml}^{-1}$, haemoglobin level $\geqslant 10 \mathrm{~g}$ per $100 \mathrm{ml}$, platelets $\geqslant 100000 \mathrm{ml}^{-1}$ ); adequate liver function (total serum bilirubin level $<1.5 \mathrm{mg}$ per $100 \mathrm{ml}$, AST and ALT $<2.5$ upper normal limit); adequate renal function (serum creatinine level $<1.5 \mathrm{mg}$ per $100 \mathrm{ml}$ ); and written informed consent. Patients with uncontrolled metabolic diseases, cardiovascular disease (uncontrolled arrhythmia, myocardial infarction within 2 years before enrolment, unstable angina, NYHA grade II or greater congestive heart failure) or active infections were excluded.

\section{Treatment}

All eligible patients received docetaxel $30 \mathrm{mg} \mathrm{m}^{-2}$ by $1 \mathrm{~h}$ intravenous (i.v.) infusion on day 1 on a weekly schedule plus estramustine phosphate $280 \mathrm{mg}$ orally two times daily from day 1 , for 12 weeks. After 2 weeks rest from the last docetaxel infusion, patients who had achieved $\geqslant 50 \%$ PSA serum value decline or had stable disease received mitoxantrone $12 \mathrm{mg} \mathrm{m}^{-2}$ by $1 \mathrm{~h}$ i.v. infusion every 3 weeks plus prednisone $5 \mathrm{mg}$ orally two times daily, continuously, up to 12 courses. Each chemotherapy sequence was discontinued in case of unacceptable toxicities or disease progression. Chemotherapy was withheld for 1 week in case of absolute neutrophil count $<1000 \mathrm{ml}^{-1}$ or if an NCI-CTC grade 2 or greater mucositis or gastrointestinal or cutaneous toxicities occurred. In the absence of recovery from toxicities within 3 weeks, patients discontinued the study. A $25 \%$ dose reduction for neutropaenic fever or any grade 3 toxicity and a $50 \%$ dose reduction for any grade 4 toxicity was recommended (except for grade 3-4 anaemia, alopecia, nausea and vomiting). Estramustine was interrupted for any grade $2-3$ toxicity and restarted at a $50 \%$ dose reduction after recovery and was definitively stopped in case of any grade 4 toxicity. The LHRH analogue previously administered was continued during the study.

\section{Evaluation}

Pretreatment evaluations included medical history, physical examination, complete blood count, serum biochemistry, PSA levels and pain evaluation according to the visual analogical scale (VAS). During docetaxel-estramustine treatment, the following were evaluated every week-physical examination, toxicity (NCICTC) record, blood count and serum biochemistry (creatinine, total bilirubin, AST, ALT, alkaline phosphatase); every 2 weeksserum PSA level; every 3 weeks-blood count, total serum biochemistry and pain evaluations (VAS). During mitoxantroneprednisone therapy, serum PSA level, blood count, total serum biochemistry and pain control (VAS) were evaluated every 3 weeks. Nuclear ventriculography (multiple-gated acquisition scanning, MUGASCAN) was performed before mitoxantrone administration and repeated at the sixth and ninth cycle.

\section{End points and response evaluation}

The primary end point of the study was PSA response defined by a decrease $\geqslant 50 \%$ from baseline, maintained for at least 4 weeks, in accordance with the consensus guidelines of the PSA Working Group (Bubley et al, 1999). PSA stabilisation was defined by a decrease $<50 \%$ or an increase $<25 \%$ from baseline, maintained for at least 4 weeks and progressive disease by an increase in serum PSA $\geqslant 25 \%$ from baseline or $\geqslant 50 \%$ from nadir, confirmed by two consecutive measurements at 2 weeks interval. Secondary end points were objective response rate according to RECIST criteria, toxicity (NCI-CTC), duration of PSA response, time to PSA progression, OS and pain control evaluations (VAS).

\section{Statistical analyses}

This was a multicentre, prospective, nonrandomised phase II clinical trial where PSA response was the primary end point. According to the Simon's minimax two-stage design with $P_{0}=50 \%, P_{1}=70 \%, \alpha=0.10$ and $\beta=0.10$, the enrolment of 23 patients was required in the first step of the study. If at least 12 objective responses were observed, a total of 39 assessable patients were enrolled. Study treatment was considered interesting if at least 24 out of 39 patients responded. Time to progression and OS were calculated from the date of first chemotherapy infusion to the date of progression or death/lost on follow-up, respectively. Time to progression and OS were analysed according to the KaplanMaier method. Response duration was calculated from the time of first objective response to the time of disease progression. An intent to treat analysis was performed.

\section{RESULTS}

\section{Characteristics of the patients and treatment}

Between September 2002 and July 2005, 40 patients from two institutions were enrolled. Median age was 72 years (range: 5583), 19 patients (47.5\%) had an ECOG performance status of 0 and 21 patients $(52.5 \%)$ had an ECOG performance status of 1 , median serum PSA level was $58 \mathrm{ng} \mathrm{ml}^{-1}$ (range: $12-912 \mathrm{ng} \mathrm{ml}^{-1}$ ), bone was the most frequent metastatic site $(68 \%), 17$ patients had a measurable disease $(43 \%), 13$ patients $(33 \%)$ had undergone previous prostatectomy and 13 patients $(33 \%)$ had received previous radiotherapy for their primary tumour. Eleven patients $(27.5 \%)$ had a VAS $\geqslant 1$ bone pain (Table 1$)$. In total, 397 courses of weekly docetaxel plus estramustine and a total of 199 three-weekly cycles of mitoxantrone plus prednisone were delivered. The 
Table I Patient characteristics

\begin{tabular}{|c|c|}
\hline & No (\%) \\
\hline No. of patients & 40 \\
\hline \multicolumn{2}{|l|}{ Age } \\
\hline Median & 72 \\
\hline Range & $55-83$ \\
\hline \multicolumn{2}{|l|}{ ECOG performance status } \\
\hline 0 & $19(47.5)$ \\
\hline I & $21(52.5)$ \\
\hline Locally advanced disease & $3(8)$ \\
\hline Metastatic disease & $37(92)$ \\
\hline \multicolumn{2}{|l|}{ Sites of disease } \\
\hline Prostate & $27(68)$ \\
\hline Bone & $27(68)$ \\
\hline Nodes & $17(43)$ \\
\hline Liver & $3(8)$ \\
\hline \multicolumn{2}{|l|}{ No. of involved organs } \\
\hline । & II (28) \\
\hline$>1$ & $29(73)$ \\
\hline \multicolumn{2}{|l|}{ Prior treatment } \\
\hline Hormone therapy & $40(100)$ \\
\hline Radiotherapy & $13(33)$ \\
\hline Prostatectomy & $13(33)$ \\
\hline \multicolumn{2}{|l|}{ Serum PSA } \\
\hline Median $\left(n g \mathrm{ml}^{-1}\right)$ & 58 \\
\hline Range & $12-912$ \\
\hline \multicolumn{2}{|l|}{ Gleason score } \\
\hline$\leqslant 7$ & $13(32.5)$ \\
\hline $8-10$ & $18(45)$ \\
\hline Not available & $9(22.5)$ \\
\hline \multicolumn{2}{|l|}{ Pain } \\
\hline VAS scale $\geqslant 1$ & II (27.5) \\
\hline
\end{tabular}

Abbreviation: ECOG = Eastern Cooperative Oncology Group.

median number of cycles per patient was 11.5 (range: $2-12$ ) for the first part of the treatment and 7 (range: $2-12$ ) for the second.

\section{Toxicity}

Docetaxel plus estramustine followed by mitoxantrone plus prednisone were overall well-tolerated. All patients (40) were assessable for toxicity after docetaxel/estramustine. Only one patient developed NCI-CTC grade 2 neutropaenia and anaemia plus grade 3 thrombocytopaenia and grade 4 stomatitis that required hospitalisation. Seven patients $(17.5 \%)$ showed a grade 3 increase of AST/ALT and/or bilirubin serum levels, resolved in four patients, after treatment delay or dose reductions. Four patients (10\%) developed deep venous thrombosis (DVT) requiring estramustine discontinuation. Twenty-seven out of 40 patients received mitoxantrone/prednisone and were assessable for toxicity. Thirteen patients did not receive this second part of the treatment due to progressive disease (five patients), severe liver toxicity unresolved after 3 weeks rest (three patients) or patient's refusal to continue (five patients). The main grade 3-4 toxicities were neutropaenia in two patients $(7 \%)$ and onycholysis in three $(11 \%)$ patients. One patient developed DVT and two patients (7\%) discontinued mitoxantrone due to the onset of congestive heart failure resolved with medical treatments. No toxic-related deaths were observed in each sequence of the planned treatment (Table 2).
Table 2 Maximum toxicity per patient

\begin{tabular}{|c|c|c|c|c|}
\hline \multirow[b]{3}{*}{ Toxicity } & \multicolumn{2}{|c|}{$\begin{array}{c}\text { Docetaxel/ } \\
\text { estramustine } \\
\text { (40 patients) }\end{array}$} & \multicolumn{2}{|c|}{$\begin{array}{c}\text { Mitoxantronel } \\
\text { prednisone } \\
\text { (27 patients) }\end{array}$} \\
\hline & GI -2 & G3-4 & GI -2 & G3-4 \\
\hline & No. (\%) & No. (\%) & No. (\%) & No. (\%) \\
\hline Neutropaenia & $4(10)$ & | (2.5) & $9(33)$ & $2(7)$ \\
\hline Thrombocytopaenia & $3(7.5)$ & I (2.5) & $3(11)$ & $0(0)$ \\
\hline Anaemia & $36(90)$ & I (2.5) & $22(81)$ & $0(0)$ \\
\hline Nausea & $28(70)$ & I (2.5) & $5(18.5)$ & $0(0)$ \\
\hline Vomiting & $20(50)$ & $0(0)$ & $2(7)$ & $0(0)$ \\
\hline Asthenia & $29(73)$ & $2(5)$ & $16(59)$ & I (4) \\
\hline Anorexia & $25(63)$ & $0(0)$ & $9(33)$ & $0(0)$ \\
\hline Diarrhoea & $24(60)$ & $0(0)$ & $7(26)$ & $0(0)$ \\
\hline Onycholysis & $9(22.5)$ & I (2.5) & $8(29)$ & $3(||)$ \\
\hline Dermatitis & $9(22.5)$ & I (2.5) & $4(15)$ & $0(0)$ \\
\hline Sensory neuropathy & $8(20)$ & $0(0)$ & $0(0)$ & $0(0)$ \\
\hline Liver toxicity & $8(20)$ & $7(17.5)$ & I (4) & $0(0)$ \\
\hline Stomatitis & $19(47.5)$ & $2(5)$ & $8(29)$ & $0(0)$ \\
\hline Deep venous thrombosis & $0(0)$ & $4(10)$ & $0(0)$ & I (4) \\
\hline Congestive heart failure & $0(0)$ & $0(0)$ & $0(0)$ & $2(7)$ \\
\hline
\end{tabular}

Table 3 PSA and objective response (RECIST)

\begin{tabular}{lcc}
\hline & No. & (\%) \\
\hline PSA response (39 patients) & & \\
PSA decline $\geqslant 90 \%$ & 15 & 37.5 \\
$95 \% \mathrm{Cl}$ & & $20-51$ \\
PSA decline $\geqslant 50 \%$ & 29 & 72.5 \\
$95 \% \mathrm{Cl}$ & & $63-82$ \\
PSA stabilisation & 7 & 17.5 \\
PSA progression & 3 & 7.5 \\
Objective response (I7 patients) & & \\
CR & 2 & 12 \\
PR & 6 & 35 \\
SD & 3 & 17 \\
CR+PR & 8 & 47 \\
95\% Cl & 6 & $35-65$ \\
PD & 6 & \\
\hline
\end{tabular}

\section{Activity}

Thirty-nine patients were assessable for PSA response. One out of 40 patients refused study treatment continuation after the onset of an allergic reaction during docetaxel first administration. Overall, twenty-nine patients $(72.5 ; 95 \%$ CI $63-82 \%)$ showed a confirmed PSA decrease $\geqslant 50 \%$ from baseline, with 15 out of 29 patients (37.5; 95\% CI 20-50\%) demonstrating a confirmed $\geqslant 90 \%$ decrease in PSA serum levels. Seven (17.5\%) patients had a PSA stabilisation and three patients (7.5\%), a PSA progression (Table 3 ). Seventeen patients had a measurable disease according to RECIST criteria. Two patients achieved a complete response (12\%), six patients showed a partial response $(35 \%)$ with an overall response rate of $47 \%$ and three patients showed a stable disease (17\%). After docetaxel/estramustine, 24 patients with a PSA response and three patients with a PSA stabilisation received mitoxantrone plus prednisone. Four patients $(10 \%)$, showing a $\geqslant 50 \%$ PSA decrease with docetaxel plus estramustine treatment, improved their response achieving a PSA decrease $\geqslant 90 \%$ during mitoxantrone/ prednisone; no patients with PSA stabilisation during docetaxel/ estramustine improved response with the second part of the treatment. Median duration of PSA response was 8.5 months (95\% 

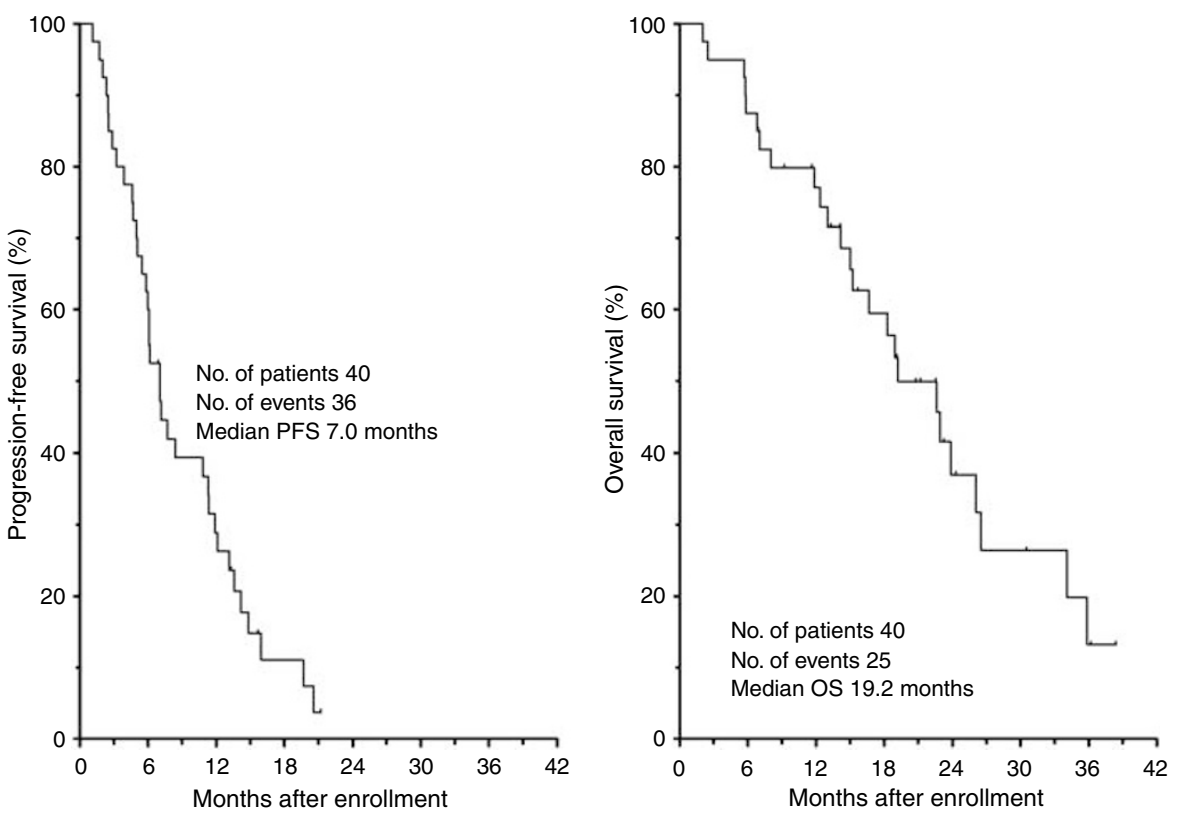

Figure I Progression-free and overall survival curves.

CI 3.85-13.10 months) in all study population and 9.4 months (95\% CI 8-10.8 months) in responder patients who had received the two chemotherapy sequences. After a median follow-up of 24.2 months, median progression-free survival was 7.0 months $(95 \% \mathrm{CI}$ 5.8 - 8.2 months) and median OS was 19.2 months (95\% CI 13.924.3 months) (Figure 1). Median progression-free survival and median OS in the 27 patients who had received the two chemotherapy sequences were 11.3 (95\% CI $6.98-15.63$ months) and 26.0 months (95\% CI 20.6-31.4 months) respectively. Moreover, the principal patterns of disease progression, in the 27 patients who received all the chemotherapy sequence, was biochemical (20 patients, $74 \%$ ), while skeletal or soft-tissue progression occurred in a minority of patients (four patients, $15 \%$ and two patients, $7 \%$ respectively). Eleven out of 40 patients $(27.5 \%)$ had a basal VAS $\geqslant 1$ bone pain and among them, median baseline VAS was 4 (range: 1-10). Eight out of 11 patients (73\%) experienced pain relief with the best response at week 4 of docetaxel/estramustine (median VAS value of 0 , range: $0-4$ ). Before receiving mitoxantrone/prednisone, 8 out of 27 patients $(29.6 \%)$ had pain with a median VAS of 2.5 (range: 1-6). Pain relief was seen in three patients $(37.5 \%)$ with best response after 1 cycle of mitoxantrone/ prednisone (median VAS value of 2, range: 1-6).

\section{DISCUSSION}

Until few years ago, chemotherapy for HRPC showed modest activity and no survival benefits and mitoxantrone plus prednisone was approved only for its palliative activity (Tannock et al, 1996; Kantoff et al, 1999). New chemotherapy regimens, such as docetaxel given every 3 weeks (Picus and Schultz, 1999) or as a weekly schedule (Beer et al, 2001), showed a PSA response rate of $46 \%$ (for both schedules) and an objective response rate of 24 and $40 \%$ respectively, in phase II studies. Moreover, its combination with estramustine demonstrated a very promising activity with manageable toxicity (Petrylak et al, 2000; Savarese et al, 2001; Sitki Copur et al, 2001; Sinibaldi et al, 2002). In particular, a randomised phase II trial of every 3 weeks or weekly docetaxel, in combination with estramustine and prednisone vs mitoxantrone and prednisone, reported a PSA response rate of $63 \%$, a time to PSA progression of 9.3 months and a median survival of 18.4 months with the weekly schedule, which also presented a good toxicity profile (Oudard et al, 2005). Recently, two randomised phase III trials have demonstrated, for the first time, a statistically significant survival advantage for docetaxel-based regimens in patients with HRPC. Docetaxel given every 3 weeks plus prednisone, demonstrated an improvement in survival (median 18.9 vs 16.4 months, $P=0.0009$ ), pain control (RR: 35 vs $22 \%$, $P=0.01)$ and PSA response rate $(45$ vs $32 \%, P<0.001)$ when compared with mitoxantrone and prednisone (Tannock et al, 2004). The second study compared docetaxel and estramustine $v s$ mitoxantrone and prednisone. A significant advantage was shown for the docetaxel-containing arm as concerning OS (median $17.5 \mathrm{vs}$ 15.6 months, $P=0.02$ ), time to progression (median 6.3 vs 3.2 months, $P<0.001)$ and PSA response rate $(50 v s 27 \%, P<0.001)$ $\left(\right.$ Petrylak et al, 2004) ${ }^{22}$. Polichemotherapy regimens have also been evaluated in HRPC patients. Combination of three or more agents yielded a biochemical response rate of $58-65 \%$ and an objective response in $32-58 \%$ of patients (Colleoni et al, 1997; Smith et al, 1999, 2003; Segawa et al, 2005). However, such schedules showed grade 3-4 haematological toxicity ranging from 12 to $48 \%$ (Smith et al, 1999, 2003; Segawa et al, 2005) with febrile neutropaenia in $15 \%$ of patients and one toxic death reported in one study (Colleoni et al, 1997). To increase the activity, but to maintain a good toxicity profile, in an often elderly and unfit population we performed the present phase II trial of sequential chemotherapy with docetaxel plus estramustine, followed by mitoxantrone and prednisone. In particular, we selected the weekly docetaxel schedule for its better toxicity profile compared to the every 3 weeks schedule. Moreover, no complete cross resistance between docetaxel and mitoxantrone has been shown in HRPC and this observation further supported our sequential design. (Michels et al, 2006; Rosenberg et al, 2006). Our regimen was feasible with a favourable toxicity profile. After docetaxel/estramustine, there were no relevant grade 3-4 haematological toxicities with the exception of a grade 3 increase in serum levels of GOT, GPT and bilirubin in seven (17.5\%) and DVT in four (10\%) patients. Mitoxantrone/prednisone, after docetaxel/estramustine, was also well tolerated in docetaxel-pretreated patients. With regard to the activity, we have observed a confirmed PSA response rate of $72.5 \%$ (95\% CI $63-82 \%)$ with a median duration of 8.5 months $(95 \%$ CI $3.85-13.1$ months) and an objective response rate of $47 \%$. Median 
progression-free survival of 7.0 months (95\% CI 5.8-8.2 months) and median OS of 19.2 months (95\% CI 13.9-24.3 months) are also interesting (Figure 1). Sequential chemotherapy was, also, evaluated in a previous phase II study in HRPC. In particular, Font et al (2005) reported in 30 patients treated with sequential mitoxantrone plus prednisone followed by every 3 weeks docetaxel plus estramustine, a PSA response rate of $23 \%$ after mitoxantrone/ prednisone with an increase to $63 \%$ after docetaxel/estramustine. The median progression-free survival was 10 months with a median survival of 18 months and the most frequent toxicity was grade 3-4 neutropaenia (13\% of patients treated with mitoxantrone/prednisone and $20 \%$ with docetaxel/estramustine). In our

\section{REFERENCES}

Beer TM, Pierce WC, Lowe BA, Henner WD (2001) Phase II study of weekly docetaxel in symptomatic androgen independent prostate cancer. Ann Oncol 12: 1273-1279

Bubley GJ, Carducci M, Dahut W, Dawson N, Daliani D, Eisenberger M, Figg WD, Freidlin B, Halabi S, Hades G, Hussain M, Kaplan R, Myers C, Oh W, Petrylak DP, Reed E, Roth B, Sartor O, Scher H, Simons J, Sinibaldi V, Small EJ, Smith MR, Trump DL, Wilding G (1999) Eligibility and response guidelines for phase II clinical trials in androgenindependent prostate cancer: recommendations from the prostatespecific antigen working group. J Clin Oncol 17: 3461-3467

Colleoni M, Graiff C, Vicario G, Nelli P, Sgarbossa G, Pancheri F, Manente P (1997) Phase II study of estramustine oral etoposide and vinorelbine in hormone refractory prostate cancer. Am J Clin Oncol 20: 383-386

Font A, Murias A, Garcia Arroyo AF, Martin C, Areal J, Sanchez JJ, Santiago JA, Constenla M, Saladie JM, Rosell R (2005) Sequential mitoxantrone/ prednisone followed by docetaxel/estramustine in patients with hormone refractory metastatic prostate cancer: results of a phase II study. Ann Oncol 16: $419-424$

Jemal A, Siegel R, Ward E, Murray T, Xu J, Smigal C, Thun MJ (2006) Cancer Statistics 2006. CA Cancer J Clin 56: 106-130

Kantoff PW, Halabi S, Conaway M, Picus J, Kirshner J, Hars V, Trump D, Winer EP, Vogelzang NJ (1999) Hydrocortisone with or without mitoxantrone in men with hormone-refractory prostate cancer: results of the cancer and leukaemia group B9182 study. J Clin Oncol 17: 2506-2513

Kreis W, Budman DR, Calabro A (1997) Unique synergism or antagonism of combinations of chemotherapeutics and hormonal agents in human prostate cancer cell lines. Br J Urol 79: 196-202

Michels J, Montemurro T, Murray N, Kollmannsberger C, Nguyen Chi K (2006) First and second line chemotherapy with docetaxel or mitoxantrone in patients with hormone refractory prostate cancer. Does sequence matter? Cancer 106: 1041 - 1046

Oudard S, Banu S, Beuzeboc B, Voog E, Dourthe LM, Hardy-Bessard AM, Linassier C, Scotté F, Banu A, Coscas Y, Guinet F, Poupon MF, Andrieu JM (2005) Multicenter randomized phase II study of two schedules of decetaxel, estramustine, and prednisone $v s$ mitoxantrone plus prednisone in patients with metastatic hormone-refractory prostate cancer. J Clin Oncol 15: 3343-3351

Petrylak DP, Shelton GB, England-Owen C (2000) Response and preliminary survival results of a phase II study of docetaxel (D) estramustine $(\mathrm{E})$ in patients with androgen-independent prostate cancer (AIPCA). Proc Am Soc Clin Oncol 19: 334a

Petrylak DP, Tangen CM, Hussain MHA, Lara PN, Jones JA, Taplin ME, Burch PA, Berry D, Moinpour RMC, Kohli M, Benson MC, Small EJ, Raghavan D, Crawford ED (2004) Docetaxel and estramustine compared with mitoxantrone and prednisone for advanced refractory prostate cancer. N Engl J Med 351: 1513 - 1520 sequential study, mitoxantrone did not contribute to increase overall schedule activity, but it seemed to be able to control advanced prostate cancer without relevant toxicity. An adequate trial incorporating time to progression or time to treatment failure as primary end point could better evaluate this chemotherapeutic strategy.

In conclusion, sequential chemotherapy with docetaxel plus estramustine followed by mitoxantrone plus prednisone is overall a well-tolerated regimen. However, although sequential use of mitoxantrone does not seem to improve docetaxel activity, its potential role as a maintenance therapy could be of interest for further studies in HRPC.
Picus J, Schultz M (1999) Docetaxel (Taxotere) as monotherapy in the treatment of hormone-refractory prostate cancer: preliminary results. Semin Oncol 26(5 suppl 17): 14-18

Pienta KJ, Smith DC (2005) Advances in prostate cancer chemotherapy: a new era begins. CA Cancer J Clin 55: 300-318

Rosenberg JE, Weinberg VK, Kelly Wk (2006) Randomized phase II study of ixabepilone or mitoxantrone and prednisone in patients with taxane resistant hormone refractory prostate cancer. Prostate Cancer Symposium February 24-26: abstract 253, pp 220

Savarese DM, Halabi S, Hars V, Akerley WL, Taplin ME, Godley PA, Hussain A, Small EJ, Vogelzang NJ (2001) Phase II study of docetaxel, estramustine, and low-dose hydrocortisone in men with hormonerefractory prostate cancer: a final report of CALGB 9780. Cancer and leukaemia group B. J Clin Oncol 19: 2509-2516

Segawa T, Kamoto T, Kinoshita H, Kunishima Y, Yoshimura K, Ito A, Takahashi T, Higashi S, Nakamura E, Nishiyama H, Ito N, Yamamoto S, Habuchi T, Ogawa O (2005) Monthly paclitaxel and carboplatin with oral estramustine phosphate in patients with hormone-refractory prostate cancer. Int J Clin Oncol 10: 333-337

Sinibaldi VJ, Carducci MA, Moore-Cooper S, Laufer M, Zahurak M, Eisenberger MA (2002) Phase II evaluation of docetaxel plus one-day oral estramustine phosphate in the treatment of patients with androgen independent prostate carcinoma. Cancer 94: 1457-1465

Sitki Copur MS, Ledakis P, Lynch J, Hauke R, Tarantolo S, Bolton M, Norvell M, Muhvic J, Hake L, Wendt J (2001) Weekly docetaxel and estramustine in patients with hormone-refractory prostate cancer. Semin Oncol 28(4 suppl 15): 16-21

Smith DC, Chay CH, Dunn RL, Fardig J, Esper P, Olson K, Pienta KJ (2003) Phase II trial of paclitaxel, estramustine, etoposide and carboplatin in the treatment of patients with hormone-refractory prostate carcinoma. Cancer 98: 269-276

Smith DC, Esper P, Strawderman M, Redman B, Pienta KJ (1999) Phase II trial of oral estramustine, oral etoposide and intravenous paclitaxel in hormone refractory prostate cancer. J Clin Oncol 17: 1664-1671

Stearns ME, Tew KD (1985) Antimicrotubule effects of estramustine, an antineoplastic tumor drug. Cancer Res 45: 3891-3897

Tannock IF, de Wit R, Berry WR, Horti J, Pluzanska A, Chi KN, Oudard S, Théodore C, James ND, Turesson I, Rosenthal MA, Eisenberger MA (2004) Docetaxel plus prednisone or mitoxantrone plus prednisone for advanced prostate cancer. $N$ Engl J Med 351: $1502-1512$

Tannock IF, Osoba D, Stockier MR, Ernst DS, Neville AJ, Moore MJ, Armitage JR, Wilson JJ, Venner PM, Coppin CML, Murphy KC (1996) Chemotherapy with mitoxantrone plus prednisone or prednisone alone for symptomatic hormone-resistant prostate cancer: a Canadian randomized trial with palliative end points. J Clin Oncol 14: $1756-1764$ 